\title{
Associations, causation and model in psychiatry
}

\author{
Associações, causas e modelos em psiquiatria \\ Dorgival Caetano', Judith Cahill², Liliana Andolpho Magalhães Guimarães³
}

\section{Keywords}

Models in mental disorders, causation in psychiatry.

\section{Palavras-chave}

Modelos de transtornos mentais, causas em psiquiatria.

\section{ABSTRACT}

This paper discusses models, associations and causation in psychiatry. The different types of association (linear, positive, negative, exponential, partial, U shaped relationship, hidden and spurious) between variables involved in mental disorders are presented as well as the use of multiple regression analysis to disentangle interrelatedness amongst multiple variables. A useful model should have internal consistency, external validity and predictive power; be dynamic in order to accommodate new sound knowledge; and should fit facts rather than they other way around. It is argued that whilst models are theoretical constructs they also convey a style of reasoning and can change clinical practice. Cause and effect are complex phenomena in that the same cause can yield different effects. Conversely, the same effect can have a different range of causes. In mental disorders and human behaviour there is always a chain of events initiated by the indirect and remote cause; followed by intermediate causes; and finally the direct and more immediate cause. Causes of mental disorders are grouped as those: (i) which are necessary and sufficient; (ii) which are necessary but not sufficient; and (iii) which are neither necessary nor sufficient, but when present increase the risk for mental disorders.

\section{RESUMO}

Este artigo discute modelos, associações e fatores causais em psiquiatria. Os diferentes tipos de associação (linear, positiva, negativa, exponencial, parcial, em forma de U, escondida e fortuita) entre as variáveis envolvidas na ocorrência de transtornos mentais são apresentados, bem como o uso da análise de regressão múltipla para analisar covariâncias entre múltiplas variáveis. Um modelo, para ser útil, deve ter consistência interna, validade externa e poder preditivo, ser dinâmico para incorporar novas descobertas e adequar-se aos fatos, e não o contrário. Os modelos, embora sejam construtos teóricos, implicam em uma dada forma de pensar e têm implicações para a prática clínica. Causa e efeito constituem um fenômeno complexo, podendo a mesma causa ter diferentes efeitos e, inversamente, o mesmo efeito, uma gama diferente de causas. Nos transtornos mentais e no comportamento humano há sempre uma cadeia de eventos iniciada por uma causa indireta e remota; seguida por causas intermediárias; e por último, uma causa direta e imediata. As causas dos transtornos mentais podem ser agrupadas em: (i) necessárias e suficientes; (ii) necessárias, mas não suficientes; e (iii) nem necessárias nem suficientes, mas se presentes, aumentam o risco para a ocorrência de transtornos mentais.

1 New South Wales University, Australia.

2 Wodonga Regional Adult Mental Health Service, Australia

Recebido em 9/4/2009

Aprovado em
$21 / 5 / 2009$ 3 Universidade Católica Dom Bosco, Brazil

Endereço para correspondência: Dorgival Caetano

New South Wales University

107 Hume Street, PO Box 1406, Wodonga, VIC 3690, Australia

Telefone: (61 02) 6049-1500; Fax: (61 02) 6056-3964

E-mail:dorgival.caetano@wrhs.org.au 


\section{MODELS AND ASSOCIATIONS}

One of the fundamental tenets of human existence is the capacity for classification through language. Classification is the basis of and understanding of the world, and enables both understanding of the past, and provides a foundation for future action. Human beings, however, are not content with only trying to explain the world. They also seek to make predictions. A model allows us to find the best explanation for the facts as we perceive them as well as make predictions.

The model is a conceptual construct for learning about a phenomenon or a set of related phenomena and enables a better grasp of the field under consideration. Models should provide the best understanding and explanation of reality as it is perceived according to current knowledge; establish logical (and when possible quantitative) relationships within the model's components; have internal consistency and external validity; predictive power strong enough to anticipate new events; and allow for inductive and deductive thinking. A good model can generate new hypotheses and also lead to new styles of reasoning and hence new clinical practice.

Models, however, are only approximation of facts and laws of nature. As our knowledge advances, new discoveries and experiments take place, and new concepts arise, models should change to accommodate these new facts. After all, models should fit the facts and not vice-versa.

A model should ascertain the relationships between the relevant phenomena/variables. Without going into statistical details, it is important to present the rationale of relationships between variables. Two phenomena (or variables) are associated or covariate when measurable changes in one phenomenon / variable concurrently occur with changes in another variable. The association between variables can be positive, negative, or fortuitous. An association is positive when concurrent changes are in the same directions (e.g., income and education level; height and weight; lung cancer and smoking, etc.); negative when they change in opposite direction (e.g. decrease in vitamin $\mathrm{C}$ consumption and scurvy). Spurious or fortuitous associations occur when the relationship between two variables $A$ and $B$ can be explained by a third variable $C$ (e.g., the association between depression and arthritis can be explained by age; as one grows older these two syndromes become more prevalent). If the effect of age is removed, the correlation between $A$ and $B$ may vanish. A fall in the temperature does not cause rain; both the fall in temperature and occurrence of rain are caused by weather change.

Likewise, the high association between drug-induced coma and death does not mean that the former causes the latter, but rather that, in general, only patients with seve- re and life threatening diseases (high intracranial pressure, pulmonary failure, etc.) are put into a drug-induced coma. Therefore, both drug-induced coma and death may be explained by a third factor - that of a severe and life threatening condition.

The degree of association between two variables can be measured by correlation coefficients: Pearson's correlation coefficient is appropriate for quantitative and normally distributed variables and Spearman's correlation coefficient is used when either the quantitative variable is not normally distributed; or either or both variables are qualitative. Correlation does not imply causation. It is only concerned with describing the strength of the linear relation between variables and has no implication with regard to cause and effect. It is important to also consider partial correlation. For example, if we only consider the relationship between the two variables education and income, we are likely to find a correlation smaller than is warranted because of the variables age and experience. Younger people, though more highly educated, may earn less than expected because of less experience in the working force. If we control for work experience and age, the relationship between education and earning becomes stronger.

Variables/phenomena may be related exponentially, that is, a small increase in $X$ leads to a high increase or decrease in $\mathrm{Y}$. Variables may also have a U-shape correlation, where up to a certain point they have a linear negative correlation and, after that point, present a positive correlation. Variables may also present as an inverted U-shape correlation, that is, they are positively correlated to a certain point, and after that point present an inverse correlation. These types of correlations warn us against extrapolation, which is defined as prediction beyond the range of observations. Anxiety and performance, and yield of crop are both good examples demonstrating the danger of extrapolation. Thus, anxiety may increase performance to a certain point, but after that point the correlation becomes negative. Likewise, irrigation may increase the crop, but too much water will decrease, rather than increase, production.

Hidden correlation further complicates the issue of relatedness between variables. Theory or intuition sometimes suggests that there should be a relationship between two variables even though the data indicate no correlation. In this case, it is possible that one or more variables are suppressing the expected relationship. For example, it may be that $A$ is not correlated with $B$, because $A$ is negatively related to $C$, which is strongly and positively related to $B$.

Partial correlation and hidden relationships show that the world cannot be reduced to a bivariate association between two variables ( $A$ and $B ; C$ and $D$ ). In fact, when it comes to human behaviour and mental disorders we always have concomitantly multiple variables carrying different weights, 
some going in the same direction and others going in the opposite direction. In addition, some of these variables may be exponentially related or present a U-shape correlation.

Even when variables are linearly correlated, the unique contribution of each variable is difficult to assess, as one variable may influence another. Using the example of the relationship between income and education, one might postulate that as younger people tend to be more highly educated, they would be expected to have higher incomes. However, the variables of age or years of work experience may weaken this relationship. The variable gender, which is also correlated with education, may have a similar effect.

A way to disentangle interrelatedness amongst multiple variables is to make use of multiple regression analysis. As an example, when we study a complex phenomenon such as schizophrenia, we are in fact dealing with a large number of variables, which we postulate may be related to the phenomenon. Using a theoretical basis (or even arbitrarily) we select a set of variables from available data to explore our hypothesis. However, even when we include all known data, it is unlikely that all relevant variables which pertain to the phenomenon have been included because there may remain a large number of unknown, yet influential, variables. For instance, several studies' reviewed clearly indicate that obstetric complications (though neither necessary, let alone sufficient to cause schizophrenia) when present increase the risk for schizophrenia and may in part explain the lack of concordance between monozygotic twins. Before these studies, researchers had not considered that this variable was relevant in exploring the causes of schizophrenia. Thus, it is important to recognise that many important variables still wait to be discovered, measured and included in the examination of mental disorder/mental health with regard to causation. Therefore, a dynamic model is warranted which can accommodate sound new knowledge.

Multiple regression analysis can assist in the study of the relationship between different sets of known variables and new variables. This technique contains criteria for the entry and removal of variables. If the first variable passes the criterion, it is selected based on highest partial correlation. When the second variable is selected, the first variable is then examined to see whether it should be removed according to the removal criterion. Following this, variables not in the equation are examined for entry. After each step, variables already in the equation are examined to assess whether they should be removed. This process continues until none remain that meet removal criteria. Variable selection terminates when no more variables meet the entry and removal criteria ${ }^{2}$. At the end of a multiple regression analysis we are left with what is the best fit of dependent variables to the independent variable. An independent variable is a variable that is thought to affect (cause) variations in the dependent variables. As an example in the treatment of depression with an antidepressant drug, the tested drug is the independent variable and changes in depression scale scores are the dependent variables.

As discussed before, association does not necessarily mean causation. A strong positive association between $A$ and $B$ does not mean that $A$ causes $B$. It could well be the other way around; or that $A$ and $B$ may vary together because a third variable $C$ affects both. On the other hand, even when apparently there is no correlation between $A$ and $B$, these variables may indeed be correlated and their correlation has been suppressed by another variable. A does not appear to be correlated with $B$ because $A$ is negatively related to $C$, which is positively related to $B$ (hidden correlation).

\section{Causation}

A causal law is any general proposition in virtue of which it is possible to infer the existence of one thing or event from the existence of another or a number of others ${ }^{3}$.

We ought whenever possible to distinguish between direct and indirect causation. Direct causation is where two events are causally connected and there are no intermediate events. However, often we have a causal chain. The Titanic did not sink for one single mistake - there was a chain of external unfavourable events and human mistakes. In psychiatry/psychology we always have intermediate causes which link the indirect and remote cause to the more immediate and direct cause, for example, alcohol-induced psychosis. Alcohol (the indirect and remote cause) leads to a chain of events (including vitamin deficiency, metabolic disturbances, etc.), which by its turn leads to other causes, and eventually to the immediate and direct cause (unknown) of the alcoholinduced psychosis. In the example of tuberculosis ${ }^{4}$, the bacterium (bacillus of Koch) brings the disease about if and only it meets with all the necessary conditions within a particular individual. If they are absent the bacterium does no harm. If the bacterium is missing, the unfavourable conditions will never be known. Without the infusion of the final cause (bacterium) the whole event would never take place. Nevertheless, it is not just produced by the final factor.

In the chain of events, any event that influences another event to a certain degree counts as part of its causation. In the causal chain there are events which are necessary and sufficient; those that are necessary but not sufficient; and those that are neither necessary, let alone sufficient, but when present increase the likelihood of the occurrence of the event/phenomenon. In mental disorders, as far as current knowledge goes, there is always a chain of events and we have to try to sort out the weight of each event and its relationship (positive, negative, partial, exponential, etc.) with the other events in the chain. Events may inhibit or enhance the manifestation of a phenomenon as well as its timing, location, speed and degree of severity. With so many known and even more unknown events in the cau- 
sal chain and their modulating (enhancing or inhibiting) factors, there should be no surprise that a given effect can have many different causes and conversely a given cause can produce many different effects. Even when we are dealing with more clear-cut phenomena, for example, endocrinologic and genetic diseases, we find that the relationship between cause and effect is complex.

Hence, hypocortisolemia (be it tertiary, secondary or primary) leads to the very same syndrome - Addison syndrome: asthenia, tiredness, anorexia, loss of weight, Gl symptoms, hypotension, hiperpigmentation and psychiatric disorders. Tertiary hypocortisolemia is due to decreased CRF secretion by the hypothalamus (due to tumour, radiotherapy, etc.); secondary hypocortisolemia to decreased ACTH secretion by the pituitary (tumour, head trauma, infections, etc.); and primary hypocortisolemia to decreased cortisol secretion by the adrenal cortex (abrupt cessation of steroids, infectious diseases, e.g. tuberculosis, HIV, autoimmune diseases, etc.). This demonstrates that a very homogeneous clinical picture (Addison syndrome) may have a great aetiological heterogeneity. Likewise, the same syndrome of beta-thalassemia can be accounted for by 28 different genetic abnormalities; and Marfan's syndrome by at least 12 different genetic abnormalities.

Genetics also reveals the inverse, that is, the same aetiology (mutation) can yield quite different clinical manifestations, as for instance in progressive muscular dystrophy. If the mutation (deletion) allows for a partial reading of the mRNA, the protein produced will be quantitatively reduced, but partially functional. However, if this deletion takes place at the point of dystrophin with membrane glycoproteins, the final result can be catastrophic ${ }^{5}$.

Again, the same genetic illness (phenotype) may have different aetiologies, that is, it results from several mutations in the same gene or even mutations in different genes. $\mathrm{Ne}$ phrogenic diabetes insipidus may be caused by as many as 180 different mutations of the vasopressin receptor gene ${ }^{6}$. In addition, modulating genetic and environmental factors may determine the extent and location of pathology, age of onset and its severity. In other words, the same genotype may give rise to a wide range of phenotypes, and conversely the same phenotype may have arisen from different genotypes.

\section{DISCUSSION}

There is not always a close relationship between homogeneity/heterogeneity in aetiology (genotype) and homogeneity/heterogeneity in symptomatology (phenotype).

Mental disorders, without exceptions, are multifactorial in that there is always a combination of genetic and environmental (biological and psychosocial) factors in their causation. From the genetic perspective, it is likely that we have multiple genes (polygenes) with small, but cumulative effect; and from the environmental perspective there is a range of biological and psychosocial factors that change overtime. Therefore, no unique combination of events is required to cause mental disorders/behavioural problems as the same phenomenon (e.g., schizophrenia) can have a number of different and simultaneous causes.

However, when we have strong and consistent associations with relationships in time (antecedent - consequent), and internal consistency, we may think of causation. Sometimes knowing the cause of a phenomenon can predict its occurrence or even prevent it from happening.

Causes in general and more specifically in mental disorders can be summarised as those, which are: (i) necessary and sufficient; (ii) necessary but not sufficient; (iii) neither necessary nor sufficient, but when present increase the chance of bringing about the phenomenon.

As an example of (i) - if a person inherits $\geq 36$ of repeats of the nucleotide triplet base CAG in a gene located in the short arm of chromosome 4, they, regardless of psychosocial influences, will invariably present with Huntington's disease. These persons would never present with this disease if they had not inherited this mutated autosomal dominant gene. Therefore, this genetic factor is necessary and at the same sufficient to cause the disease. Group (ii) can be demonstrated in schizophrenia. The average concordance for schizophrenia in monozygotic twins (MZ) is $50 \%$. This indicates that genetics, though necessary, is not, by itself, sufficient to cause schizophrenia. If it were, MZ twins should be $100 \%$ concordant. Finally, group (iii) can be illustrated by obstetric complications (OC), which have been shown to increase the risk for schizophrenia. Some MZ twins with schizophrenia had a history of OC; whereas the healthy ones did not. Most schizophrenic patients, however, do not have a history of $O C$, which indicates that $O C$ is not necessary for the presentation of schizophrenia'. Moreover, OC may be present in other mental disorders than schizophrenia such as ADHD, mental disability, epilepsy, and so on. This indicates the non-specificity of OC. However, though nonspecific, $\mathrm{OC}$ increases the risk for these disorders.

With regard to mental disorders, we have several (genetic and environmental) concomitant causes and none of them fall into category (i). The interrelationship amongst these causes will be discussed in a future paper dealing with the bio-psycho-social model.

\section{CONCLUSION}

In conclusion, the study of associations and causality in psychiatry can only be possible by making use of multivariate statistical techniques which enable us to more fully understand and disentangle the complex contribution of biological, psychological and social factors which all impact, 
in varying degrees, upon mental disorders and the mental health of the individual.

\section{REFERENCES}

1. Caetano D, Lacerda ALT, Stella F. Etiopatogenia das psicoses: fatores genéticos e ambientais. In: Garcia R, Pondé M, Lima MG, eds. Atualização em psicoses. São Paulo: Phoenix, 2004. p. 35-47.
2. Norusis MJ. Statistical Package for the Social Sciences for Windows: Base system user's guide. Chicago, IL: SPSS Inc:;1993.

3. Russell B. Our knowledge of the external world. London: Allen \& Unwin; 1952.

4. Jaspers K. General Psychopathology: vol II. Baltimore: The Johns Hopkins University Press; 1997.

5. McNally EM, Passos-Bueno MR, Bönnemann CG, Vainzof M, de Sá Moreira E, Lidov HG, et al. Mild and severe muscular dystrophy caused by a single gamma-sarcoglycan mutation. Am J Hum Genet. 1996;59(5):1040-7.

6. Knoers NVAM; Deen PMT. Molecular and cellular defects in nephrogenic diabetes. Pediatr Nephrol. 2001;16(12):1146-52. 